\title{
Model Regresi Energi Potensial Minimum pada Permukaan Hasil Interpolasi
}

\author{
Endang Rusyaman, Ema Carnia, Kankan Parmikanti \\ Program Studi S1 Matematika FMIPA UniversitasPadjadjaran \\ Jalan Raya Bandung Sumedang KM 21 JatinangorSumedang \\ erusyaman@yahoo.co.id,,ema_carnia@yahoo.com, parmikanti@yahoo.co.id
}

\begin{abstract}
ABSTRAK
Jika beberapa titik pada sebuah permukaan elastis berbentuk persegi ditekan dari bawah, maka akan terbentuk sebuah permukaan baru yang dapat dinyatakan sebagai fungsi dua variabel hasil interpolasi yang meminimumkan energi. [2], [4], dan [6]. Energi potensial yang diformulasikan sebagai integral dari kuadrat operator Laplace dan diperluas menjadi orde fraksional ini, akan dipengaruhi oleh besarnya tekanan dan elastisitas permukaan. Makalah ini membahas tentang besarnya pengaruh dua variabel bebas yaitu tekanan dan elastisitas terhadap variabel terikat yaitu energi potensial yang terbentuk, serta bagaimana hubungan ketiga variabel tersebut yang dinyatakan dalam bentuk model regresi. Dengan terlebih dahulu mengkarakterisasi orde turunan fraksional menjadi tiga klasifikasi, maka telah dihasilkan tiga buah model untuk tiga keadaan. Dari ketiga model regresi yang dihasilkan menunjukkan bahwa pengaruh bersama variabel elastisitas (orde fraksional) dan variabel besaran tekanan terhadap energi potensial minimum adalah cukup besar, yaitu diatas $85 \%$. Sisanya adalah pengaruh lain yang belum terduga.
\end{abstract}

Kata kunci: energi, elastisitas, fraksional, pemodelan, sinus ganda

\begin{abstract}
If some points on a square-shaped elastic surface is pressed from the bottom, it will form a new surface that can be expressed as a function of two variables interpolated by minimizing the energy.[2], [4], and [6]. Potential energy was formulated as the integral of the square of the Laplace operator and expanded into a fractional order, will be affected by the amount of pressure and surface elasticity. This paper discusses the influence of two independent variables, namely pressure and surface elasticity with respect the dependent variable ie potential energy, and how the relationship of these three variables that expressed in regression model. By first characterizing the fractional-order derivatives into three classifications, it has produced three models for the three condition. From the three regression models produced, showed that the influence of elasticity variable (fractional order) and pressure variable together with respectthe minimum potential energy is large enough, is above $85 \%$. The rest is yet another run expected effect.
\end{abstract}

Keywords: Energy, elasticity, fractional, regression modelling, double sinus

\section{Pendahuluan}

Dalam makalah ini, yang dimaksud dengan interpolasi dari fungsi dua variabel $f(x, y)$ dengan $u(x, y)$ adalah mengkonstruksi sebuah fungsi berbentuk deret sinus ganda berderajat tak hingga yaitu $u(x, y)$ sedemikian sehingga nilai-nilai fungsi $u(x, y)$ di $\left(x_{i}, y_{i}\right)$ sama dengan nilai-nilai $f(x, y)$ di $\left(x_{i}, y_{j}\right)$ untuk semua $i=1,2, . ., n$ dan $i=1,2, . ., \mathrm{m}$. Dalam hal ini $u(x, y)$ dikatakan sebagai interpolan dari $f(x, y)$. Pada prakteknya, pencarian $u(x, y)$ ini ditambahkan syarat-syarat tertentu, yaitu sedemikian sehingga interpolasi ini meminimumkan nilai $E_{\beta}(u)$, dimana

$$
E_{\beta}(u):=\int_{0}^{1} \int_{0}^{1}\left|(-\Delta)^{\beta / 2} u\right|^{2} d x d y
$$


di mana $\Delta=\frac{\partial^{2}}{\partial x^{2}}+\frac{\partial^{2}}{\partial y^{2}} \quad$ yang disebut operator Laplace, sedangkan $\beta$ adalah orde turunan fraksional dari $u(x, y)$.

Persamaan (1) adalah bentuk lain dari energi potensial pada permukaan [6], di mana permukaan yang dimaksud adalah permukaan yang terbentuk setelah sebuah permukaan datar elastis ditekan dari bawah di beberapa titik berbeda seperti tampak pada Gambar 1.

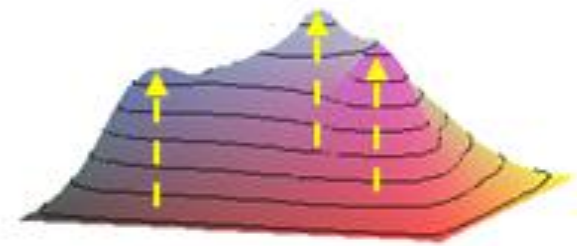

Gambar 1. Permukaan Ditekan di Tiga Titik

Apabila besarnya tekanan dari bawah tersebut sebesar $C$ satuan, sedangkan elastisitas permukaan adalah $\beta$, maka besarnya energi potensial pada permukaan yang dinotasikan $E_{\beta}$ akan tergantung pada nilai $C$ dan $\beta$. Dalam makalah ini akan diperlihatkan model regresi yang menyatakan hubungan tersebut.

Tujuan dibuatnya model ini adalah untuk mengetahui sejauhmana hubugan ketiga variabel di atas, serta mempermudah perhitungan energi, tanpa harus menggunakan perhitungan numerik menggunakan software dengan ratusan bahkan ribuan iterasi yang telah dibuat pada penelitian sebelumnya [ 2,4$]$.

\section{Metode Penelitian: Eksistensi Fungsi Interpolan $u(x, y)$}

Pada penelitian terdahulu, Rusyaman dkk dalam [2] serta Gunawan dkk dalam [4], telah menjamin eksistensifungsi hasil interpolasi berbentuk permukaan yang dinyatakan sebagai deret sinus ganda

$$
u(x, y):=\sum_{m=1}^{\infty} \sum_{n=1}^{\infty}\left[a_{m n} \sin m \pi x \sin n \pi y\right]
$$

dengan $0 \leq y \leq 1$ dan $0 \leq x \leq 1$, serta meminimumkan nilai energi seperti yang dinyatakan dalam (1). Dengan $u$ seperti pada (2), maka energi tersebut menjadi

$$
E_{\beta}(u)=\frac{1}{4} \pi^{2 \beta} \sum_{m=1}^{\infty} \sum_{n=1}^{\infty} a_{m n}^{2}\left(m^{2}+n^{2}\right)^{\beta}
$$

Untuk menjamin eksistensi solusi, pertama-tama didefinisikan ruang fungsi

$$
W_{\beta}:=\left\{u(x, y)=\sum_{m=1}^{\infty} \sum_{n=1}^{\infty} a_{m n} \sin m \pi x \sin n \pi y \mid \sum_{m=1}^{\infty} \sum_{n=1}^{\infty}\left(m^{2}+n^{2}\right)^{\beta} a_{m n}{ }^{2}<\infty\right\} .
$$

yang kemudian ditunjukkan bahwa $W_{\beta}$ ini merupakan ruang Hilbert dengan hasil kali dalam

di mana

$$
\langle u, v\rangle=\sum_{m=1}^{\infty} \sum_{n=1}^{\infty}\left(m^{2}+n^{2}\right)^{\beta} a_{m n} b_{m n},
$$

dan

$$
u(x, y)=\sum_{m=1}^{\infty} \sum_{n=1}^{\infty} a_{m n} \sin m \pi x \sin n \pi y
$$




$$
v(x, y)=\sum_{m=1}^{\infty} \sum_{n=1}^{\infty} b_{m n} \sin m \pi x \sin n \pi y .
$$

Kekontinuan fungsi $u(x, y)$ untuk setiap $k$ pada $W_{\beta}$ akan sangat tergantung pada $\beta$, dimana penetapan nilai $\beta$ diberikan melalui lema berikut.

\section{Lema 1}

Deret ganda $\sum_{m=1}^{\infty} \sum_{n=1}^{\infty} \frac{1}{\left(m^{2}+n^{2}\right)^{\beta}} \quad$ adalah konvergen untuk $\beta>1$.

\section{Teorema 1}

Untuk $\beta>1$, jika $\left(u_{k}\right)$ konvergen ke u dalam norma, maka $\left(u_{k}\right)$ konvergen seragam ke $u$.

\section{Bukti:}

Diketahui $\left(u_{k}\right)$ konvergen dalam norma ke $u$, maka

$$
\lim _{k \rightarrow \infty}\left\|u_{k}-u\right\|=0 \text {. }
$$

Berarti untuk setiap $\varepsilon>0$ ada $n_{0} \in \mathbf{N}$ sehingga untuk $k>n_{0}$ berlaku $\left\|u_{k}-u\right\|<\varepsilon$.

Jadi untuk $k>n_{0}$ tersebut dan untuk setiap $x, y \in[0,1]$ berlaku:

$$
\begin{gathered}
\left|u_{k}(x, y)-u(x, y)\right|=\left|\sum_{m=1}^{\infty} \sum_{n=1}^{\infty}\left(a_{m n}^{k}-a_{m n}\right) \sin m \pi x \sin n \pi y\right| \\
=\left|\sum_{m=1}^{\infty} \sum_{n=1}^{\infty}\left(m^{2}+n^{2}\right)^{\beta / 2}\left(a_{m n}^{k}-a_{m n}\right) \frac{\sin m \pi x \cdot \sin n \pi y}{\left(m^{2}+n^{2}\right)^{\beta / 2}}\right| \\
\leq\left[\sum_{m=1}^{\infty} \sum_{n=1}^{\infty}\left(m^{2}+n^{2}\right)^{\beta}\left(a_{m n}^{k}-a_{m n}\right)^{2}\right]^{1 / 2}\left[\sum_{m=1}^{\infty} \sum_{n=1}^{\infty} \frac{\sin ^{2} m \pi x \sin ^{2} n \pi y}{\left(m^{2}+n^{2}\right)^{\beta}}\right]^{1 / 2} \\
\leq\left\|u_{k}-u\right\|\left[\sum_{m=1}^{\infty} \sum_{n=1}^{\infty} \frac{1}{\left(m^{2}+n^{2}\right)^{\beta}}\right]^{1 / 2}
\end{gathered}
$$

Berdasarkan Lema-1, deretganda $\sum_{m=1}^{\infty} \sum_{n=1}^{\infty} \frac{1}{\left(m^{2}+n^{2}\right)^{\beta}}<\infty$ untuk $\beta>1$, maka

$$
\left|u_{k}(x, y)-u(x, y)\right| \leq \mathrm{C}\left\|u_{k}-u\right\| \text {. }
$$

Karena $C$ tidak tergantung pada $x$ dan $y$, maka $\left(u_{k}\right)$ konvergen seragam ke $u$.

Sebelum menyajikan teorema eksistensi solusi, terlebih dahulu diberikan lema berikut yang menunjukkan syarat perlu bagi dipenuhinya eksistensi solusi tersebut.

\section{Lema 2}

Subruang dari $W_{\beta}$, yaitu

$$
V=\left\{u(x, y) \in W_{\beta} \mid u\left(x_{i}, y_{j}\right)=0, i=1,2, \ldots, M, j=1,2, \ldots, N\right\}
$$

adalah tutup, sedangkan himpunan bagian dari $W_{\beta}$ yaitu

$$
U=\left\{u(x, y) \in W_{\beta} \mid u\left(x_{i}, y_{j}\right)=\mathrm{c}_{i j}, i=1,2, \ldots, M, j=1,2, \ldots, N\right\}
$$

adalah tak kosong, tutup, dan konveks. 
Selanjutnya, berdasarkan lema di atas serta berdasarkan [1] dan [3] diperoleh teorema berikut.

\section{Teorema 2}

Masalah minimisasi energi (3) memiliki solusi tunggal di $W_{\beta}$, dan solusi tersebut adalah
\[ \begin{array}{c}u=u_{0}-\operatorname{proj} v\left(u_{0}\right)\end{array} \]

dengan $u_{0}$ adalah sebuah unsur sembarang dari $U$ dan proj $v\left(u_{0}\right)$ menyatakan proyeksi orthogonal dari $u_{0}$ ke $V$.

\section{Bukti}

Misalkan $u_{0}$ adalah sebuah unsur di $U$. Maka untuk suatu $v \in V, u_{0}-v$ adalah juga di $U$. Karena $U$ adalah himpunan bagian yang konveks dari $W_{\beta}$, maka harus terdapat unsur yang tunggal $v_{0} \in V$ sedemikian sehingga $\left\|u_{0}-v_{0}\right\|$ adalah norma terkecil. Jadi $u=u_{0}-v_{0}$ adalah solusi tunggal di $W$ dalam masalah minimisasi (3). Berdasarkan teori aproksimasiter baik dalam ruang Hilbert [1], unsur $v_{0} \in V$ yang membuat nilai $\left\|u_{0}-v_{0}\right\|$ minimum adalah proyeksi orthogonal dari $u_{0}$ pada $V$, yaitu $v_{0}=\operatorname{proj} v\left(u_{0}\right)$

Setelah adanya jaminan tentang eksistensi fungsi $u(x, y)$ dalam teknisnya untuk mencari fungsi solusi tersebut digunakan sistem iterasi sampai diperoleh nilai energi yang minimum.

\section{Hasil dan Pembahasan}

\subsection{Permasalahan}

Untuk menentukan dan menghitung nilai energi potensial minimum pada penelitian sebelumnya, yaitu pada [2] dan [3], harus menggunakan software melalui ratusan bahkan ribuan iterasi sehingga kurang efektif baik dalam sisi proses maupun waktu. Dengan demikian perlu dibuatkan suatu model yang relatif memudahkan perhitungan. Model yang akan dibuat adalah model regresi yang selain dapat menyederhanakan perhitungan berdasarkan data yang valid, juga dapat mengetahui sejauh mana hubugan antar variabelnya [5]. Permasalahan utama yang akan diuraikan dalam makalah ini adalah sebagai berikut.

Misalkan diberikan sebuah permukaan berupa sebuah plat elastic berbentuk segi empat. Selanjutnya permukaan tersebut ditekan dari bawah tepat di tengah-tengah. Tentu saja di setiap titik pada permukaan tersebut akan terjadi energi sebaliknya yang mengarah ke bawah. Besarnya energi ini akan tergantung pada dua hal, yaitu besarnya tekanan pada permukaan yang dinotasikan dengan $C$, dan elastisitas permukaan yang dapat diidentikkan dengan orde turunan fraksional yang dinotasikan dengan $\beta$. Demikian pula apabila permukaan ditekan di dua atau tiga titik yang berbeda, dengan asumsi tekanan yang diberikan pada dua atau tiga titik tersebut sama besar, maka besarnya energi akan tetap tergantung pada dua hal di atas.

Secara matematik, apabila permukaan elastis berbentuk persegi diletakkan pada garis-garis $x=0, x=a, y=0$ dan $y=b$, kemudian titik tengahnya ditekan dari bawah, maka permukaan yang terjadi akan tampak seperti pada Gambar 1.

Menurut Langhar [6], permukaan yang terjadi setelah ditekan dapat di representasikan dengan deret sinus ganda

$$
w=\sum_{m=1}^{\infty} \sum_{n=1}^{\infty} a_{m n} \sin \frac{m \pi x}{a} \sin \frac{n \pi y}{b}
$$


yang memenuhi isyarat batas $w=0, w_{x x}=0$, untuk $x=0, x=a, y=0$ dan $y=b$. Energi tegangan pada permukaan plat yang mengarah ke bawah adalah

$$
E=\frac{1}{2} D \int_{0}^{a} \int_{0}^{b}\left(w_{x x}+w_{y y}\right)^{2} d x d y=\frac{1}{2} D \int_{0}^{a} \int_{0}^{b}(\Delta w)^{2} d x d y
$$

Dengan $D$ adalah elastisitas permukaan plat, sehingga berdasarkan (1) diperoleh

$$
E=\frac{1}{8} \pi^{4} a b D \sum_{m=1}^{\infty} \sum_{n=1}^{\infty}\left(\frac{m^{2}}{a^{2}}+\frac{n^{2}}{b^{2}}\right) a_{m n}^{2}
$$

Pembahasan masalah dibagi dalam tiga bagian, yaitu:

1. Permukaan ditekan dari bawah di satu titik, yaitu tepat di titik $\left(\frac{1}{2}, \frac{1}{2}, 1\right)$ sejauh satu satuan,sehingga energi hanya tergantung pada $\beta$ saja.

2. Permukaan ditekan dari bawah di dua titik yang berbeda, sejauh $\mathrm{C}$ satuan yaitu di $\left(\frac{1}{4}, \frac{1}{2}, \mathrm{C}\right)$ dan $\left(\frac{3}{4}, \frac{1}{2}, \mathrm{C}\right)$, sehingga energi tergantung pada $\beta$ dan $\mathrm{C}$.

3. Permukaan ditekan dari bawah di tiga titik yang berbeda, sejauh $\mathrm{C}$ satuan, yaitu di titik $\left(\frac{1}{4}, \frac{1}{4}, \mathrm{C}\right),\left(\frac{1}{3}, \frac{2}{3}, \mathrm{C}\right)$ dan $\left(\frac{3}{4}, \frac{1}{2}, \mathrm{C}\right)$. Dalam hal ini pun energi tergantung pada $\beta$ dan $\mathrm{C}$.

\subsection{Pembahasan}

\subsubsection{Masalah 1: Permukaan Ditekan di Satu Titik}

Pada masalah pertama, diberikan sebuah permukaan berupa sebuah plat elastic berbentuk segiempat yang diletakkan pada garis-garis $x=0, x=1, y=0$, dan $y=1$. Selanjutnya titik tengah plat ditekan dari bawah ke atas sejauh $C=1$ satuan seperti pada Gambar 2 di bawah, sehingga titik puncak maksimum berada di tengah-tengah bidang, tepatnya dengan koordinat $\left(\frac{1}{2}, \frac{1}{2}, 1\right)$.

Permukaan yang terbentuk diasumsikan sebagai fungsi seperti pada (2) dan besarnya energi permukaan seperti pada (3). Besarnya nilai energy $E_{\beta}$ akan sangat tergantung pada nilai $\beta$. Tanpa mengurangi keumuman dengan menghilangkan konstanta $\pi^{2 \beta}$ dari persamaan (3), melalui perhitungan yang telah diuraikan pada [2] dan [4] serta menggunakan software sampai iterasi-1225, diperoleh data berupa 20 buah besaran energi minimum yang dihasilkan dari 20 nilai $\beta$ dengan sebaran antara 1.00 dan 2.00 .

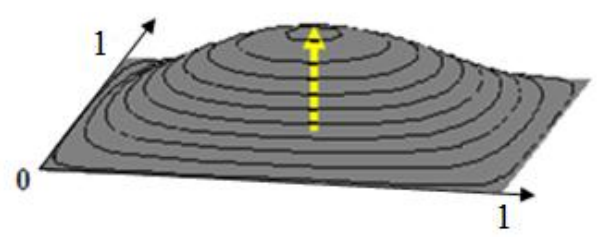

Gambar 2 Permukaan Ditekan di Satu 


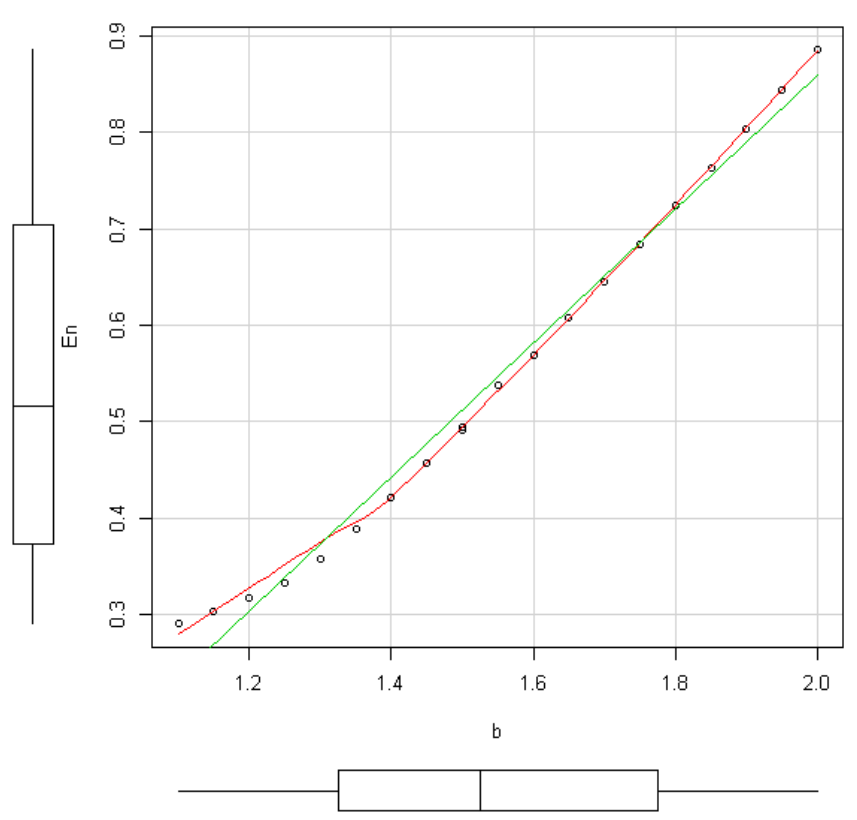

Gambar 3 Titik Diagram Pencar

Diagram pencar tampak seperti pada Gambar (3) di atas, di mana Garis berwarna merah menunjukkan garis kuadrat terkecilnya, sedangkan garis hijau menunjukkan garis regresi linear. Hasil analisis data menunjukkan bahwa korelasi antara $\beta$ dan $E_{\beta}$ bernilai positif sebesar 0.9939006 , artinya saling mempengaruhi secara berbanding lurus karena nilainya mendekati 1 , artinya semakin besar nilai $\beta$ maka akan semakin besar nilai $E_{\beta}$.

Dengan residual standar error 0.02163 , dan derajat kebebasan 18, serta multiple $\mathrm{R}$-squared sebesar 0.9878 maka dihasilkan nilai intercept $=-0.52547$ dan koefisien $\beta=0.69240$. Dengan demikian model regresi linearnya adalah:

$$
E_{\beta}=-0,52547+0,69240 \beta
$$

\subsubsection{Masalah-2: Permukaan Ditekan di Dua Titik}

Pada masalah kedua, diberikan sebuah permukaan berupa sebuah plat elastic berbentuk segiempat yang diletakkan pada garis-garis $x=0, x=1, y=0$, dany $=1$ seperti tampak pada Gambar 4. Selanjutnya plat ditekan dari bawah ke atas di dua titik yang berbeda yaitu $\left(\frac{1}{4}, \frac{1}{2}\right)$ dan $\left(\frac{3}{4}, \frac{1}{2}\right)$ sejauh $C$ satuans eperti pada Gambar 5 berikut, sehingga dua titik puncak memiliki koordinat $\left(\frac{1}{4}, \frac{1}{2}, \mathrm{C}\right)$ dan $\left(\frac{3}{4}, \frac{1}{2}, \mathrm{C}\right)$ dan besarnya nilai energy $E_{\beta}$ akan sangat tergantung pada nilai $\beta$ dan $C$.

Hasil analisis data menunjukkan bawa korelasi antara $\beta$ dan $E_{\beta}$ bernilai positif 0,1778537 artinya kurang mempengaruhi secara berbanding lurus karena nilainya relatif kecil, 
sedangkan korelasi antara $C$ dengan $E_{\beta}$ lebih baik karena nilainya mendekati adalah 0.8507899. Karena nilai korelasinya positif, maka hal ini berarti bahwa baik $\beta$ maupun $C$ sama-sama berbanding lurus dengan dengan $E_{\beta}$. Dengan demikian, makin besar nilai $\beta$ dan $C$ maka semakin besar pula nilai $E_{\beta}$.
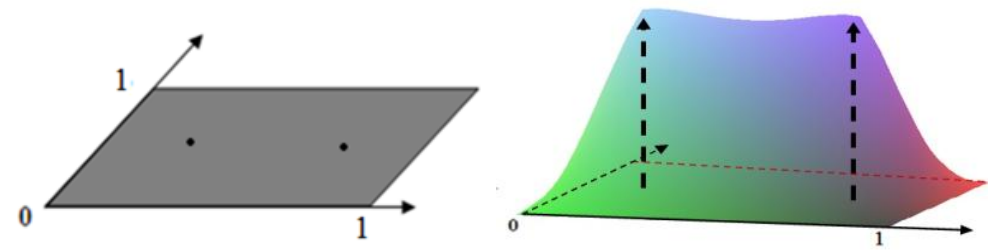

Gambar-4 Permukaan yang Ditekan di Dua Titik

Dengan residual standar error 0.2518 , dan derajat kebebasan 22 , serta multiple $\mathrm{R}$ - squared sebesar 0.8528 , berarti pengaruh nilai $\beta$ dan $C$ secara bersama-sama terhadap $E_{\beta}$ cukup besar yaitu $85,3 \%$. Nilai intercept yang dihasilkan $=-1.5651$, dan nilai koefisien $\beta=0.0 .6978$, serta nilai koefisien $C=1.8696$. Dengan demikian model regresi linearnya adalah:

$$
E_{\beta}=-1.5651+0.0 .6978 \beta+1.8696 C
$$

\subsubsection{Masalah-3: Permukaan ditekan di tiga titik}

Pada masalah ketiga, diberikan sebuah permukaan berupa sebuah plat elastic berbentuk segiempat yang diletakkan pada garis-garis $x=0, x=1, y=0$, dan $y=1$. Selanjutnya plat ditekan dari bawah ke atas di tiga titik yang berbeda yaitu $(0.25,0.25),(0.33,0.67)$ dan $(0.75$, 0.50) sejauh $C$ satuan seperti pada Gambar 1 di atas, sehingga tiga titik puncak memiliki koordinat $(0.25,0.25, C),(0.33,0.67, C)$ dan $(0.75,0.50, C)$. Seperti halnya pada masalah dua titik, besarnya nilai energy $E_{\beta}$ akan sangat tergantung pada nilai $\beta$ dan $C$.

Hasil analisis data menunjukkan bawa korelasi antara $\beta$ dan $E_{\beta}$ bernilai positif 0.2774373 artinya kurang mempengaruhi secara berbanding lurus karena nilainya relative kecil, sedangkan korelasi antara $C$ dengan $E_{\beta}$ lebih baik karena nilainya mendekati adalah 0.8131555 . Karena nilai korelasinya positif, maka hal ini berarti bahwa baik $\beta$ maupun $C$ samasama berbanding lurus dengan dengan $E_{\beta}$. Dengan demikian, makin besar nilai $\beta$ dan $C$ maka semakin besar pula nilai $E_{\beta}$.

Dengan residual standar error 0.2104 , dan derajat kebebasan 22, serta multipleR-squared sebesar 0.8578 maka dihasilkan nilai intercept $=-1.5348$, nilai koefisien $\beta=0.7362$, dan nilai koefisien $C=1.6467$. Dengan demikian model regresi linearnya adalah:

$$
E_{\beta}=-1.5348+0.7362 \beta+1.6467 C
$$

\section{Simpulan}

Hasil pengolahan data dan analisis model menghasilkan kesimpulan bahwa nilai orde turunan fraksional yaitu $\beta$, dapat diidentikkan dengan elastisita permukaan seperti dinotasikan dengan $D$ pada persamaan (2) dan (3). Selain itu nilai $\beta$ dan $C$ (besarnya tekanan 
dari bawah) berbanding lurus dengan besarnya energi minimum $E_{\beta}$, artinya semakin kaku bahan permukaan, dan semakin besar tekanan yang diberikan, maka akan semakin besar nilai energinya.

\section{Ucapan Terima Kasih}

Terima kasih kepada Rektor Universitas Padjadjaran yang telah membiayai penelitian ini melalui DIPA Unpad No. 023.04.2/189726/2013.

\section{Daftar Pustaka}

1. Atkinson. K, \& Han. W., 2001, Theorical Numerical Analysis A Functional Analysis Framework, Springer Verlag, New York.

2. E. Rusyaman, H. Gunawan, A.K. Supriatna, R.E. Siregar, 2009, A 2-D Interpolation Method That Minimizes An Energy Integral, Presented at IICMA, Yogyakarta.

3. Gunawan. H, Pranolo.F, Rusyaman.E, 2007, An Interpolation Method That Minimizes an Energy Integral of Fractional Order. Singapore: Proceeding of Asian Symposium of Computer Mathematics,

4. H. Gunawan, E. Rusyaman \& L. Ambarwati, (2011), Surfaces with Prescribed Nodes and Minimum Energy Integral of Fractional Order, ITB J. Sci., Vol. 43 A, No. 3, page 209-222.

5. Hogg and Craig, 1995, Introduction to Mathematical Statistics, Prentice-Hall, New Jersey.

6. Langhaar.H.L, 1962, Energy Methods in Applied Mechanics, John Wiley \& Sons, New York. 